\title{
Thermal diffusivity and electron transport properties of NTC samples obtained by photoacoustic method
}

\section{S.M. Savić1 ${ }^{\text {, D.T. Luković }}{ }^{1}$, O.S. Aleksić, V.Ž. Pejović}

\begin{abstract}
${ }^{1}$ Institute of Technical Sciences of SASA, Knez Mihailova 35/IV, 11000 Belgrade, Serbia and Montenegro
${ }^{2}$ Center for multidisciplinary studies of the University of Belgrade, Kneza Višeslava 1, 11000 Belgrade, Serbia and Montenegro
\end{abstract}

\section{Abstract}

Thermal diffusivity and electron transport parameters of sintered NTC samples were determined by the photoacoustic technique. Powder mixtures composed of $\mathrm{MnO}$, NiO, $\mathrm{CoO}$ and $\mathrm{Fe}_{2} \mathrm{O}_{3}$ were milled to nanometer particle size. NTC discs were dry powder pressed and sintered at different temperatures in the range from $900^{\circ} \mathrm{C}$ to $1200^{\circ} \mathrm{C}$ for 30 minutes. A second group of NTC discs was sintered at $1200^{\circ} \mathrm{C}$ with the sintering time varying from 30 to 240 minutes. These NTC samples were polished and exposed to a chopped laser beam in order to plot a response in the acoustic range. The thermal diffusivity of sintered NTC layers based on a metal oxide powder mixture was measured at room temperature by the photoacoustic (PA) technique. An increase of thermal diffusivity with sintering temperature and time of sintering was observed.
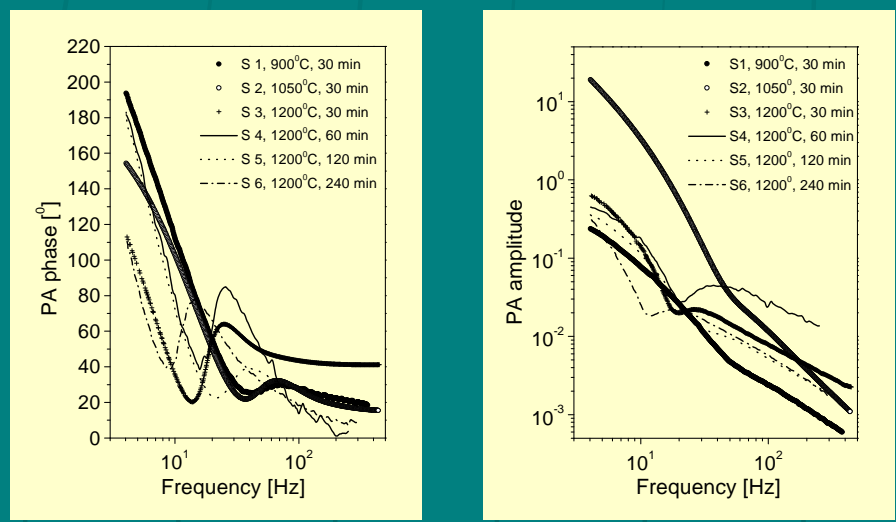

Experimental phase and amplitude PA diagrams for NTC samples sintered in different conditions

Values of calculated parameters for sintered NTC samples

\begin{tabular}{|c|c|c|c|c|c|}
\hline Sample & $T\left[{ }^{\circ} \mathrm{C}\right] / \boldsymbol{t}[\mathrm{min}]$ & $D_{T}\left[\mathrm{~m}^{2} / \mathrm{s}\right]$ & $\tau[\mathrm{s}]$ & $\Delta\left[\mathrm{m}^{2} / \mathrm{s}\right]$ & $\mu\left[\mathrm{cm}^{2} / \mathrm{Vs}\right]$ \\
\hline 1 & $900 / 30$ & $0.35 \times 10^{-6}$ & $0.85 \times 10^{-2}$ & $0.47 \times 10^{-7}$ & $1.8 \times 10^{-2}$ \\
\hline 2 & $1050 / 30$ & $0.68 \times 10^{-6}$ & $0.78 \times 10^{-2}$ & $0.27 \times 10^{-8}$ & $2.7 \times 10^{-4}$ \\
\hline 3 & $1200 / 30$ & $0.73 \times 10^{-6}$ & $0.20 \times 10^{-1}$ & $0.34 \times 10^{-7}$ & $1.3 \times 10^{-2}$ \\
\hline 4 & $1200 / 60$ & $0.83 \times 10^{-6}$ & $0.10 \times 10^{-1}$ & $0.82 \times 10^{-8}$ & $3.2 \times 10^{-3}$ \\
\hline 5 & $1200 / 120$ & $0.87 \times 10^{-6}$ & $0.14 \times 10^{-1}$ & $0.32 \times 10^{-8}$ & $1.3 \times 10^{-3}$ \\
\hline 6 & $1200 / 240$ & $0.88 \times 10^{-6}$ & $0.12 \times 10^{-1}$ & $0.30 \times 10^{-8}$ & $1.2 \times 10^{-3}$ \\
\hline
\end{tabular}
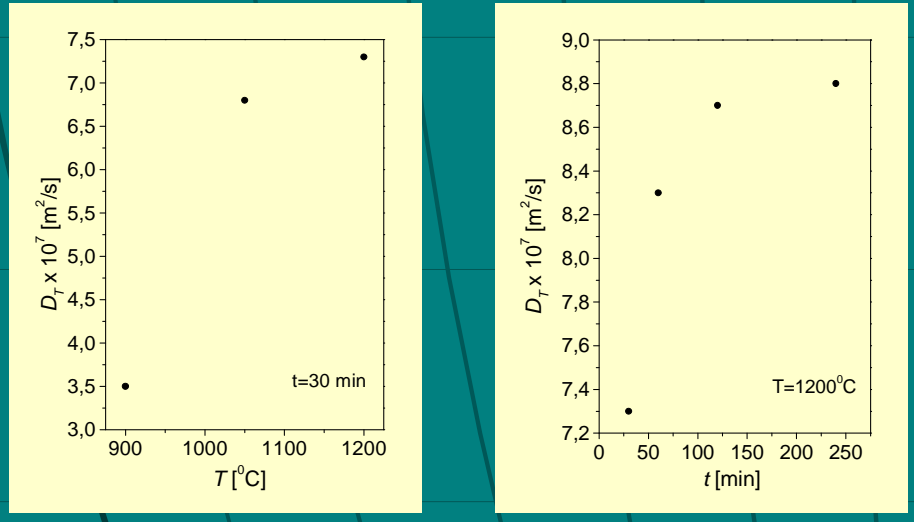

a)

Thermal diffusivity vs. temperature (a) and time of sintering (b) for different NTC samples

\section{Experimental}

$>$ Powder preparation:

-Calcinating $\left(1050^{\circ} \mathrm{C}, 60 \mathrm{~min}\right)$

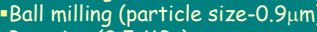

- Pressing (2.5 MPa)

- Sintering conditions $\left(900^{\circ} \mathrm{C}, 1050^{\circ} \mathrm{C}, 1200^{\circ} \mathrm{C}\right.$ - $30 \mathrm{~min}$; $\left.1200^{\circ} \mathrm{C}-30,60,120,240 \mathrm{~min}\right)$

$>$ SEM (JEOL JSM 6460LV)

$>$ Photoacoustic measurements
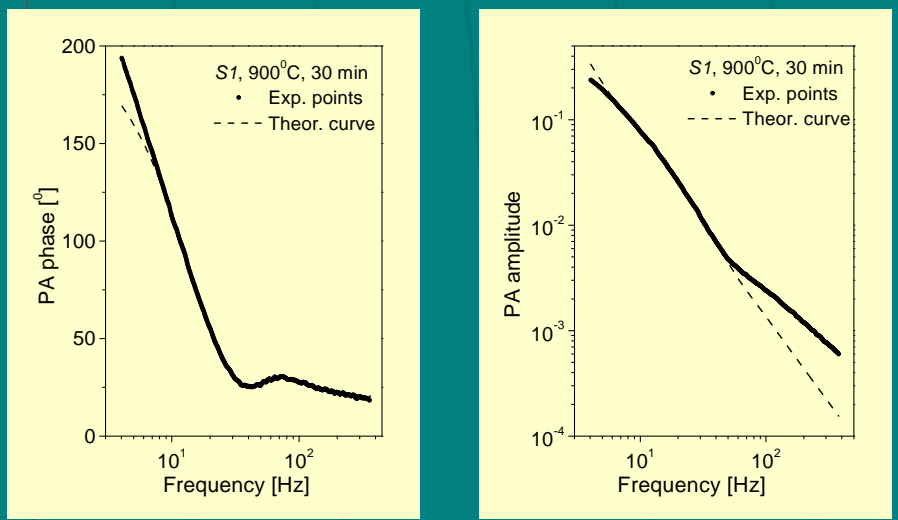

Experimental (points) and theoretical (dashed line) phase and amplitude PA diagrams for a NTC sample sintered at $900^{\circ} \mathrm{C}$ for 30 minutes.
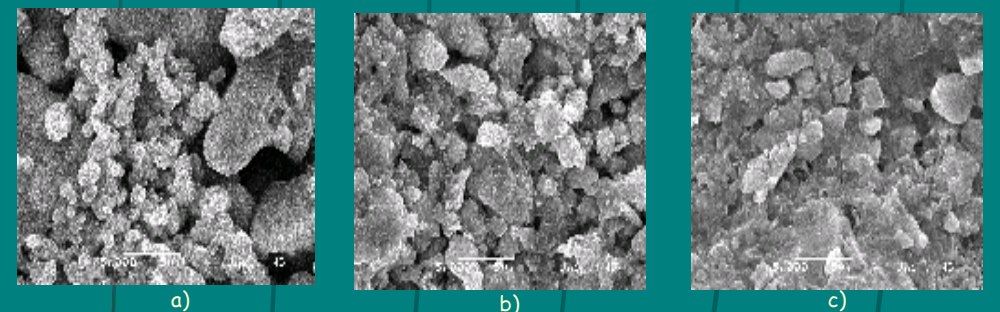

SEM images obtained from surfaces of $900^{\circ} \mathrm{C}(\mathrm{a}), 1050^{\circ} \mathrm{C}$ (b) and $1200^{\circ} \mathrm{C}$ (c).
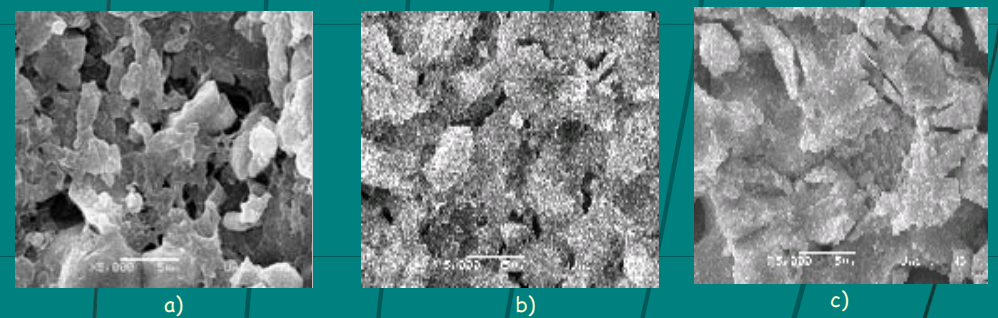

SEM images obtained from surfaces of samples sintered at $1200^{\circ} \mathrm{C}$ for different times: $60 \mathrm{~min}(\mathrm{a}), 120 \mathrm{~min}$ (b) and $240 \mathrm{~min}$ (c)

\section{Conclusion}

$>$ The behavior of sintered NTC thermistors and changes in the microstructure after sintering are connected/with thermal diffusivity and electronic transport properties

$>$ Thermal diffusivity increases when the temperature and time of sintering rise $>$ This is a consequence of a corresponding microstructure-increase in interparticle contact, average grain/size, material density and reduction of porosity when temperature and time of sintering rise 